\title{
A threat-response multi-criteria funding model for homeland security grant programs
}

\author{
Madjid Tavana \\ Professor and Lindback Distinguished Chair of Information Systems, \\ La Salle University, 1900 West Olney Avenue, Philadelphia, PA 19141, USA \\ E-mail: tavana@lasalle.edu \\ URL: http://lasalle.edu/ tavana
}

Received 21 February 2006; received in revised form 21 December 2006; accepted 28 December 2006

\begin{abstract}
The Department of Homeland Security (DHS) provides funding to 50 states, the District of Columbia, and seven US territories through a consolidated program called the Homeland Security Grant Program (HSGP). There has been much controversy about the lack of structure in HSGP and the method it employs to allocate funds to the states and territories. Slice is a threat-response multi-criteria decision model that systematically evaluates the threats and responses of securing the states and territories. The Analytic Hierarchy Process (AHP) and probability elicitation methods are used to capture the objective and subjective judgments used in Slice. The probability calibration and entropy methods are used along with the utility theory to obtain a composite weighted score for each state and territory. These weighted scores are combined with the population scores in a structured framework to determine the amount of funding for the states and territories.
\end{abstract}

Keywords: multi-criteria decision-making; threat-response analysis; homeland security funding; analytic hierarchy process; probability calibration; entropy method; utility theory

\section{Introduction}

The attacks of September 11, 2001 have drastically heightened the US Government's fears of possible terrorist threats. The range of possible attack scenarios is undeniably complex and their probabilities are extremely difficult to quantify. There has been no shortage of recommendations from both federal and state governments as to the best strategy for protecting the United States. The Department of Homeland Security (DHS) was established to provide the unifying core for the vast national network of organizations and institutions involved in efforts to secure the United States. The DHS leverages resources within federal, state, and local governments by coordinating

(C) 2007 The Authors.

Journal compilation (C) 2007 International Federation of Operational Research Societies.

Published by Blackwell Publishing, 9600 Garsington Road, Oxford, OX4 2DQ, UK and 350 Main St, Malden, MA 02148 , USA. 
the transition of multiple agencies and programs into a single, integrated agency focusing on protecting the homeland. DHS assists state and local jurisdictions to prevent, respond to, and recover from incidents of terrorism involving chemical, biological, radiological, nuclear, or explosive weapons, and cyber attacks. DHS allocates its national budget between 50 states, the District of Columbia, and seven US territories through a consolidated program called the Homeland Security Grant Program (HSGP). There has been much controversy about the lack of structure in HSGP and the method it employs to allocate funds to the states and territories.

Approximately $\$ 2.5$ billion each year is allocated through the SHGP among the states and territories. Financial allocations in 2003 and 2004 were based on a formula that consisted of guaranteeing each state a $0.75 \%$ amount of total program appropriations and the remainder of appropriations based on the state's population percentage of the national population. In 2005, Congress required DHS to allocate funding in the same manner as in 2004. In 2006, DHS decided to allocate funding to states based on risk and need, rather than on population. Each state would receive no less than $0.25 \%$ of total program appropriation. The current approach evaluates both risks to assets as well as risks to populations and geographic areas. Coats et al. (2006) and Kersten (2005) argue that this minimum state allocation process is inefficient and results in uneven per capita allocations. In addition to this inefficiency, the minimum state allocation process sends funds to more rural areas at less risk (Roberts, 2005).

Tensions between different branches of government over homeland security funding allocation criteria and mechanisms are abundant. Evaluating multiple programs competing for scarce resources and selecting those programs that will satisfy conflicting objectives is a difficult and complex task. This process is even more complex in the government sectors because it may reflect political issues resulting in the exclusion of technical or more rational considerations. Almost all stakeholders agree that a more rational funding system based on threat, vulnerability and risk of terror attack, and population is needed (Brunet, 2005; Reese, 2005; Clarke and Chenoweth, 2006). However, the critical question remains unanswered, how much money should states and territories receive for terrorism prevention and preparedness?

The primary goal in multi-criteria decision-making (MCDM) is to provide a set of criteria aggregation methodologies for considering the preferential system and judgments of decision makers (DMs) (Doumpos and Zopounidis, 2002). This is a difficult task requiring the implementation of complex processes. Although intuition and simple rules are still popular decision-making methods, they may be dangerously inaccurate for complex decisions such as homeland security. Roy (1990) argues that solving MCDM problems is not searching for an optimal solution, but rather helping DMs master the complex judgments and data involved in their problems and advance toward an acceptable solution. Multi-criteria analysis is not an offthe-shelf recipe that can be applied to every problem and situation. Methods should be chosen carefully according to the quantity and quality of the available judgments and data, the nature of the problem, and the expectations of the DMs. The development of MCDM models is often dictated by real-life problems. Therefore, it is not surprising that methods have appeared in a rather diffuse way, without any clear general methodology or basic theory (Vincke, 1992).

Traditionally, MCDM frameworks fall into three categories: the multi-objective value analysis (Keeney and Raiffa, 1976), the outranking method (Vincke, 1992), and the interactive methods (Vanderpooten and Vincke, 1989). The selection of a framework depends on the nature of the problem including the type of choices, measurement scales, importance weights, dependency 
among the criteria, and the type of uncertainty (Vincke, 1992). The integration of several mathematically sound techniques can reduce the difficulties in the selection of an appropriate framework. Finding the "best" MCDM framework is an elusive goal that may never be reached (Triantaphyllou, 2000). Pardalos and Hearn (2002) discuss the importance of exploring ways of combining criteria aggregation methodologies to enable the development of models that consider the DM's preferential system in complex problems. Belton and Stewart (2002) also argue the need for integrating frameworks in MCDM.

Slice $^{1}$ is a MCDM model that systematically considers the threats and responses of securing the states and territories into a structured framework to determine the amount of funding for the states and territories. Slice is not intended to imply a deterministic approach to homeland security funding allocation. Homeland security funding is a complex problem requiring compromise and negotiation between stakeholders from various branches of government. Slice creates an even playing field to pursue consensus. The analytical processes in Slice help DMs decompose complex MCDM problems into manageable steps, making this model accessible to a wide variety of situations. Although technical details of Slice are complex, the basic concepts are not difficult to understand. As such, the DMs can use available analytical tools and techniques with some assistance from the experts (Schoemaker and Russo, 1993). The objective and subjective judgments captured by Slice are processed with the Analytic Hierarchy Process (AHP), Probability Calibration, the Entropy Method, and Utility Theory to obtain a composite weighted score for each state and territory. These weighted scores are combined with population scores in a structured framework to determine the amount of funding for the states and territories and to create an even playing field for pursuing consensus.

\section{Procedure and model description}

Slice utilizes environmental scanning to identify and quantify the relevant threats and responses associated with each state and territory receiving funding from the DHS. Environmental scanning is the acquisition and use of information about opportunities and threats in an organization's external environment, the knowledge of which would assist management in planning the organization's future course of action (Aguilar, 1967; Albright, 2004). Environmental scanning is an early warning system that scans the environment systematically and identifies new and unexpected threats and responses. Effective environmental scanning provides the strategic intelligence needed for Slice to understand and assess current and potential threats and responses. A nine-step procedure systematically evaluates potential threats and responses by calculating an allocation score associated with each recipient. The allocation scores are then used in the model to allocate federal homeland security funds to each state and territory. Details for calculating these scores are presented in the next section. The nine steps associated with Slice are as follows:

(1) Define program-related weights.

(2) Identify threats and responses within each program.

\footnotetext{
${ }^{1}$ The model is referred to as "Slice" because it attempts to provide each state or territory with their share (slice) of the total program budget (pie).
} 
(3) Define subjective weights associated with the threats and responses.

(4) Develop a set of subjective probabilities for the threats and responses.

(5) Calibrate the subjective probabilities of the threats and responses.

(6) Revise the subjective weights of the threats and responses with their intrinsic weights.

(7) Measure the risk-aversion constant of the threats and responses.

(8) Calculate the allocation score of each recipient.

(9) Allocate funds according to the normalized allocation and population scores.

Each of these steps is described below.

(1) Define program-related weights: Initially, the subjective weights representing the relative importance of the HSGPs for the threats $\left(W_{c_{i}}^{\prime}\right)$ and responses $\left(W_{b_{i}}^{\prime}\right)$ are determined. In the past, such weights have been assessed directly by DMs using a scale ranging from $0=$ unimportant to 1 = important (David, 1986, 1993). Slice uses AHP (Saaty, 1989, 1994; Saaty and Vargas, 2001) to calculate these weights. An advantage of AHP is its capability to measure the consistency of the DM while making pairwise comparisons of the relative importance of the programs. AHP is a widely used technique and an earlier survey listed well over 200 applications of AHP in the literature (Zahedi, 1986). Assuming that $c_{1}, c_{2}, \ldots, c_{g}$ are the $g$ programs that contribute to the overall goal of homeland security, the DM's goal is to assess their relative importance.

First, the DM compares each possible pair $c_{j}, c_{k}$ of programs and provides judgments about which programs are more important and by how much. AHP quantifies these judgments and represents them in a $g \times g$ matrix:

$$
A=\left(a_{j k}\right) \quad(j, k=1,2, \ldots, g) .
$$

If $c_{j}$ is judged to be of equal importance as $c_{k}$, then $a_{j k}=1$; if $c_{j}$ is judged to be more important than $c_{k}$, then $a_{j k}>1$; and if $c_{j}$ is judged to be less important than $c_{k}$, then $a_{j k}<1$.

$$
a_{j k}=1 / a_{k j}, \quad a_{j k} \neq 0 .
$$

Because the entry $a_{j k}$ is the inverse of the entry $a_{k j}$, the matrix $A$ is a reciprocal matrix. $a_{j k}$ reflects the relative importance of $c_{j}$ compared with program $c_{k}$. Next, the vector $w$ representing the relative weights of each of the $g$ programs can be found by computing the normalized eigenvector corresponding to the maximum eigenvalue of matrix $A$. An eigenvalue of $A$ is defined as $\lambda$ which satisfies the following matrix equation: $A w=\lambda w$, where $\lambda$ is a constant, called the eigenvalue, associated with the given eigenvector $w$. Saaty (1983) has shown that the best estimate of $w$ is the one associated with the maximum eigenvalue $\left(\lambda_{\max }\right)$ of the matrix $A$. Because the sum of the weights should be equal to 1.00 , the normalized eigenvector is used.

AHP encourages DMs to be consistent in their pairwise comparisons. Saaty (1983) suggests a measure of consistency for the pairwise comparisons. When the judgments are perfectly consistent, the maximum eigenvalue, $\lambda_{\max }$, should equal $g$, the number of programs that are compared. In general, the responses are not perfectly consistent, and $\lambda_{\max }$ is greater than $n$. The larger the $\lambda_{\max }$, the greater is the degree of inconsistency. Saaty (1983) defines the consistency index $(\mathrm{CI})$ as $\left(\lambda_{\max }-g\right) /(g-1)$, and provides a random index (RI) table for matrices of order 3 to 10. The RIs are based on a simulation of a large number of randomly generated weights. Saaty (1983) recommends the calculation of a consistency ratio (CR), which is the ratio of CI to the RI for the same order matrix. A CR of 0.10 or less is considered acceptable. When the CR is 
unacceptable, the DM is made aware that the pairwise comparisons are logically inconsistent and is encouraged to revise them.

There has been some criticism of AHP in the operations research literature. Harker and Vargas (1987) show that AHP does have an axiomatic foundation, the cardinal measurement of preferences is fully represented by the eigenvector method, and the principles of hierarchical composition and rank reversal are valid. On the other hand, Dyer (1990a) has questioned the theoretical basis underlying AHP and argues that it can lead to preference reversals based on the alternative set being analyzed. In response, Saaty (1990a) explains how rank reversal is a positive feature when new reference points are introduced. Slice employs the geometric aggregation rule to avoid the controversies associated with rank reversal (Dyer 1990a, b, Harker and Vargas 1990, Saaty 1990b). Alternatively, AHP can be easily replaced with any other appropriate weight assessment method in Slice.

(2) Identify threats and responses within each program: A major difficulty in MCDM is when decision criteria are grouped into opposite categories, usually called "cost" and "benefit" criteria. In this study, a "threat" is considered a cost criteria and a "response" is considered a benefit criteria. Threats have an increasing effect in Slice while responses have a reducing effect in the model. In general, higher probabilities of occurrence for threats results in more funding while higher probabilities of occurrence for responses results in less funding for a recipient. For example, a higher probability of occurrence for a threat factor such as "Threat of attack on skyscrapers" should result in more funding to a state or territory. In contrast, a higher probability of occurrence for a response factor such as "Responsiveness of disaster recovery plans" should result in less funding to a state or territory.

(3) Define subjective weights associated with the threats and responses: Next, the subjective importance weights associated with the threats $\left(\bar{W}_{c_{i j}}^{\prime \prime}\right)$ and responses $\left(\bar{W}_{b_{i j}}^{\prime \prime}\right)$ are determined. Again, AHP is used to simplify this subjective estimation process by confining the DMs' judgments concerning the pairwise comparisons of threats and responses within each program. Direct derivation could be used to derive the $W^{\prime}$ s objectively and directly from the $W^{\prime \prime}$ s in small problems. However, in large problems, direct derivation is cumbersome and infeasible as AHP requires $\frac{n^{2}-n}{2}$ pairwise comparisons where $n$ is the number of factors to be compared (Saaty, 1990a). The measure of inconsistency provided by AHP allows for the examination of inconsistent priorities.

(4) Develop a set of subjective probabilities for the threats and responses: Next, the probability of occurrence for the potential threats $\left(P_{c_{i j}}^{m}\right)$ and responses $\left(P_{b_{i j}}^{m}\right)$ associated with the grant programs are estimated by the DMs. The probability estimation process takes place once a year concurrent with the fund allocation process. Such subjective assessments are often used in strategic decision making (McGlashan and Singleton, 1987). Slice utilizes probabilistic phrases, like "impossible," "possible," and "certain" to elicit required information and then convert them into numeric probabilities as suggested by many researchers (Beyth-Marom, 1982; Brun and Teigen, 1988; Budescu and Wallsten, 1985; Lichtenstein and Newman, 1967; Tavana et al., 1997). Alternatively, the DM may use numeric probabilities instead of the probabilistic phrases. The subjective probability associated with a factor is assumed binomial in Slice. Binomial probabilities are commonly used in strategic decision making because the DM can simplify the problem by analyzing possible outcomes as either occurring or not occurring. For example, Schoemaker (1993) assigns binomial probabilities to factors such as "Dow Jones Industrial Average falling 
below 1500 mark by 1990" or “Election of a Democrat as US president by 1990." Vickers (1992) also assigns binomial probabilities to similar factors such as "Japanese car manufacturers gain at least $30 \%$ of the European market share" and "The incorporation of East Europe into Europe by 1993 " in order to examine the future of the European automobile industry. The main motivation for using the binomial probabilities is to reduce the complexity of the model.

(5) Calibrate the subjective probabilities of the threats and responses: Next, Slice calibrates the subjective probabilities found in the previous step according to the following procedure. Defining $P_{c_{i j}}^{m}$ as the probability of occurrence of a threat factor such as the probability of attack on skyscrapers in state or territory $m,\left(1-P_{c_{i j}}^{1}\right)\left(1-P_{c_{i j}}^{2}\right) \ldots\left(1-P_{c_{i j}}^{q}\right)$ is the probability of no attack on skyscrapers in any state or territory. Then, $P_{c_{i j}}=1-\left(1-P_{c_{i j}}^{1}\right)\left(1-P_{c_{i j}}^{2}\right) \ldots\left(1-P_{c_{i j}}^{q}\right)$ is the probability of at least one attack in the entire set of the states and territories. Now, let $P_{c_{i j}}^{*}$ be an independent expert assessment of the probability of a skyscraper attack in the entire set of states and territories. $\Delta P_{c_{i j}}=P_{c_{i j}}^{*}-P_{c_{i j}}$ is the discrepancy between this independent expert assessment and the probability of a skyscraper attack computed from the probabilities of skyscraper attack in the states and territories.

$P_{c_{i j}}$ can then be revised to be equal to $P_{c_{i j}}^{*}$ by finding the value of $x$ such that $P_{c_{i j}}^{*}=1-\left(1-x P_{c_{i j}}^{1}\right)\left(1-x P_{c_{i j}}^{2}\right) \ldots\left(1-x P_{c_{i j}}^{q}\right)$. In other words, the probability of a skyscraper attack in each state or territory is revised upward or downward so that the revised $P_{c_{i j}}=P_{c_{i j}}^{*}$. If $P_{c_{i j}}^{*}>P_{c_{i j}}$, the probabilities are revised upward so that $x>1$ and if $P_{c_{i j}}^{*}>P_{c_{i j}}$, the probabilities are revised downward so that $x<1$.

(6) Revise the subjective weights of the threats and responses with their intrinsic weights: Next, the objective importance weights associated with the threats $\left(\hat{W}_{c_{i j}^{\prime \prime}}^{\prime \prime}\right)$ and responses $\left(\hat{W}_{b_{i j}^{\prime \prime}}^{\prime \prime}\right)$ are determined. Slice uses the entropy method to determine the importance weights associated with the threats and responses without the direct involvement of the DMs in terms of the probabilities of potential threats $\left(P_{c_{i j}}^{m}\right)$ and responses $\left(P_{b_{i j}}^{m}\right)$. The essential idea is that the objective importance of a threat or response is a direct function of the information conveyed by the threat or response relative to the entire set of $q$ states and territories. This means that the greater the dispersion in the probabilities, the more important the threat or response. In other words, the most important threats or responses are those that have the greatest discriminating power between the states and territories.

In this method, a set of objective importance weights associated with the threats and responses are determined without the direct involvement of the DMs. However, this is a complete contradiction to the notion that weights should represent the relative importance the DMs attach to the threats or responses. Therefore, the subjective weights representing the judgments of DMs obtained by the AHP are multiplied by the values of weights (intrinsic weights) obtained by the entropy method. The final result, once normalized, is used in Slice to represent the importance weight of the threats and responses.

Each threat or response is an information source; therefore, the more information a threat or response reveals, the more relevant it is. Zeleny (1982) argues that this intrinsic information must be used in parallel with the subjective weights the DMs assigns to various threats and responses. In other words, the overall importance weight of a threat $\left(W_{i_{i j}^{\prime \prime}}^{\prime \prime}\right)$ or response $\left(W_{b_{i j}}^{\prime \prime}\right)$ is directly related to the intrinsic weight of the threat $\left(\hat{W}_{c_{i j}^{\prime \prime}}^{\prime \prime}\right)$ or response $\left(\hat{W}_{b_{i j}}^{\prime \prime}\right)$, reflecting the average intrinsic information provided by the probabilities, and the subjective weights of the threat $\left(\bar{W}_{c_{i j}}^{\prime \prime}\right)$ or response $\left(\bar{W}_{b_{i j}}^{\prime \prime}\right)$, reflecting the subjective importance weights assigned by the DM. 
The more different the probabilities of a threat or response are for a set of states and territories, the larger is the contrast intensity of the threat or response, and the greater is the amount of information transmitted by that threat or response. A similar procedure is applied to calculate the intrinsic weight of the responses. Assuming that the vector $p_{c_{i j}}=\left(p_{c_{i j}}^{1}, \ldots, p_{c_{i j}}^{q}\right)$ characterizes the $i$ th program, the $j$ th threat, and the $q$ th state or territory, the entropy measure for a given $i$ and $j$ is:

$$
e\left(p_{c_{i j}}\right)=-K \sum_{k=1}^{q} \frac{p_{c_{i j}}^{k}}{p_{c_{i j}}} \ln \frac{p_{c_{i j}}^{k}}{p_{c_{i j}}},
$$

where $p_{c_{i j}}=\sum_{k=1}^{q} p_{c_{i j}}^{k}, i=1,2, \ldots, g$ and $j=1,2, \ldots, N_{c_{i}}$, and $K>0$, ln is the natural logarithm, $0 \leqslant p_{c_{i j}}^{k} \leqslant 1$, and $e\left(p_{c_{i j}}\right) \geqslant 0$. When all $p_{c_{i j}}^{k}$ are equal for a given $i$ and $j$, then $p_{c_{i j}}^{k} / p_{c_{i j}}=1 / q$, and $e\left(p_{c_{i j}}\right)$ assumes its maximum value, which is $e_{\max }=\ln q$. By setting $K=1 / e_{\max }$, we achieve $0 \leqslant e\left(p_{c_{i j}}\right) \leqslant 1$ for all $p_{c_{i j}}$ 's. This normalization is necessary for meaningful comparisons. In addition, the total entropy is defined as

$$
E=\sum_{j=1}^{N_{c_{i}}} e\left(p_{c_{i j}}\right) \text {. }
$$

The smaller $e\left(p_{c_{i j}}\right)$ is, the more information the $j$ th threat transmits in the $i$ th program, and the larger $e\left(p_{c_{i j}}\right)$ is, the less information it transmits. When $e\left(p_{c_{i j}}\right)=e_{\max }=\ln q$, the $j$ th threat in the $i$ th program transmits no useful information. Next, the intrinsic weight is calculated as follows:

$$
\hat{W}_{c_{i j}}^{\prime \prime}=\frac{1}{N_{c_{i}}-E}\left[1-e\left(p_{c_{i j}}\right)\right],
$$

where $N_{c_{i}}$ is the total number of threats for program $i$.

Because $\hat{W}_{c_{i j}}^{\prime \prime}$ is inversely related to $e\left(p_{c_{i j}}\right), 1-e\left(p_{c_{i j}}\right)$ is used instead and normalized to ensure $0 \leqslant \hat{W}_{c_{i j}}^{\prime \prime} \leqslant 1$ and $\sum_{j=1}^{N_{c_{i}}} \hat{W}_{c_{i j}}^{\prime \prime}=1$. The higher $e\left(p_{c_{i j}}\right)$, the less information content is provided by the $j$ th threat in the $i$ th program. When the information content of the $j$ th threat in the $i$ th program is low, the corresponding intrinsic weight $\left(\hat{W}_{c_{i j}}^{\prime \prime}\right)$ should be low. Thus, the intrinsic weight is assumed to be inversely related to the entropy. Therefore, Slice uses $1-e\left(p_{c_{i j}}\right)$ in the definition of the intrinsic weight.

The more different the probabilities $P_{c_{i j}}^{k}$ are, the larger $\hat{W}_{c_{i j}}^{\prime \prime}$ is and the more important the $j$ th threat in the $i$ th program is. When all the probabilities, $P_{c_{i j}}^{k}$, are equal for the $j$ th threat in the $i$ th program, then, $\hat{W}_{c_{i j}}^{\prime \prime}=0$ for that threat. However, this is not true if the probabilities $P_{c_{i j}}^{k}$ are equal for all the threats $j$. In that case, the weights are assumed to be equal or $\hat{W}_{c_{i j}}^{\prime \prime}=1 / N_{c_{i}}$ where $N_{c_{i}}$ is the number of threats for a given program. Entropy multiplies the intrinsic weight $\left(\hat{W}_{c_{i j}}^{\prime \prime}\right)$ by the subjective weight $\left(\bar{W}_{c_{i j}}^{\prime \prime}\right)$ and normalizes the product to calculate the overall importance weight of the $j$ th threat in the $i$ th program $\left(W_{c_{i j}}^{\prime \prime}\right)$,

$$
W_{c_{i j}}^{\prime \prime}=\frac{\hat{W}_{c_{i j}}^{\prime \prime} \cdot \bar{W}_{c_{i j}}^{\prime \prime}}{\sum_{j=1}^{N_{c_{i}}} \hat{W}^{\prime \prime} \cdot \bar{W}_{c_{i j}^{\prime \prime}}^{\prime \prime}} .
$$

There are two other methods for calculating the intrinsic weights of the threats and responses. Diakoulaki et al. (2000) proposes a method based on the correlation between the columns of the decision matrix. The other method measures the importance of each threat or response as a member of a coalition by means of the Shapley value (Grabisch and Roubens, 1999). Slice uses the 
entropy method suggested by Zeleny (1982, Ch. 7) because it is readily available in MCDM, provides consistent results, and is easily accepted by DMs (Pomero and Brba-Romero, 2000, Ch. 4).

(7) Measure the risk-aversion constant of the threats and responses: Assuming the DM is averse to risk and his or her utility function is exponential, the DM's risk-aversion constant is calculated as $\left(r_{c_{i j}}\right)$ for each threat and $\left(r_{b_{i j}}\right)$ for each response. Certainty equivalence $(\mathrm{CE})$, probability equivalence $(\mathrm{PE})$, gain equivalence $(\mathrm{GE})$, and loss equivalence (LE) are among the various techniques that could be used to measure the risk-aversion constant (Hershey et al., 1989). We prefer using CE as it is suggested by Bodily (1985). According to CE, the DM is offered a scenario where there are two possible outcomes. The first has an outcome of 1.0 with a probability of 0.5 and the second has an outcome of 0 with a probability of 0.5 , where 1 represents the occurrence and 0 represents the non-occurrence of a threat or response. Given the expected value of $0.50(1)+0.50(0)=0.50$ for the above scenario, the DM is asked to provide his or her CE between 0 and $0.50 . \mathrm{CE}=0$ represents complete risk-aversion $(r=\infty)$ while $\mathrm{CE}=0.50$ represents complete risk-neutrality $(r=0)$. Assuming $\mathrm{CE}$ is equal to $p$ and the DM's utility function is given by $u(p)=\frac{1}{r}\left(1-e^{-r p}\right)$, the value of $r$ that satisfies the given $\mathrm{CE}$ using $e^{-r p}-0.5 e^{-r}=0.5$ can be found. This equation is derived by setting the utility of the CE, $u(p)=\frac{1}{r}\left(1-e^{-r p}\right)$, equal to the expected utility of the scenario, expected utility $=0.5 u(1)+0.5 u(0)$. It is always recommended to use more than one kind of question or approach to assure that the risk-aversion constant represents the feelings of the DM.

The DM's risk-aversion constant $(r)$ is assumed to be greater than 0 , representing aversion toward risk. Slice does not consider $r=0$, which represents risk neutrality, or $r<0$, which represents preference toward risk, a behavior which is not evident in real life (Gupta and Cozzolino, 1974).

(8) Calculate the allocation score of each recipient: Next, the allocation score $\left(A^{m}\right)$ of each recipient is calculated by dividing the total threats $\left(C^{m}\right)$ of a program by its total responses $\left(B^{m}\right)$ multiplied by the standard deviation of the allocation scores $\left(S^{m}\right)$. The allocation score is a measure of the overall threats and responses in a recipient's environment. The larger the value of the allocation score, the more dollars are allocated to the recipient. The total threats and responses are in turn calculated by summing the multiplication of the relative weight of each program to the relative weight of each threat or response within that program and the calibrated subjective probability of that threat or response for the selected recipient.

The standard deviation is a composite measure of the spread of the weights and probabilities associated with the threats and responses within a program. The higher the standard deviation, the more uncertainty is associated with the environment. The recipient with a higher standard deviation, representing greater unknowns and uncertainties in its environment, receives more funding than a recipient with a lower standard deviation and a more predictable and certain environment. All the weights, probabilities, and scores used in our model are organized in a tabular form and are presented in Table 1.

The mathematical details of the weighted sum model used to calculate the allocation scores is presented next. Given:

$A^{m}=$ The allocation score of the $m$ th recipient

$C^{m}=$ The total weighted threats of the $m$ th recipient 
Table 1

Representation of the relevant information used in Slice

\begin{tabular}{|c|c|c|c|c|c|c|}
\hline & $\begin{array}{l}\text { Program } \\
\text { weight }\end{array}$ & $\begin{array}{l}\text { Threat } \\
\text { weight }\end{array}$ & $\begin{array}{l}\text { Risk-aversion } \\
\text { constant }\end{array}$ & Recipient 1 & $\ldots$ & Recipient $q$ \\
\hline \multicolumn{7}{|l|}{ Costs } \\
\hline Program 1 & $W_{c_{1}}^{\prime}$ & & & & & \\
\hline Threat 1 & & $W_{c_{11}}^{\prime \prime}$ & $r_{c_{11}}$ & $P_{c_{11}}^{1}$ & $\ldots$ & $P_{c_{11}}^{q}$ \\
\hline$\cdots$ & & $\cdots$ & $\cdots$ & $\cdots$ & $\cdots$ & $\cdots$ \\
\hline Threat $N_{c_{1}}$ & & $W_{c_{1 N_{c_{1}}}}^{\prime \prime}$ & $r_{c_{1 N_{c_{1}}}}$ & $P_{c_{1 N_{c_{1}}}}^{1}$ & & $P_{c_{1 N c_{1}}}^{q}$ \\
\hline$\cdots$ & & $\ldots$ & $\cdots$ & $\ldots$ & $\cdots$ & $\ldots$ \\
\hline $\begin{array}{l}\cdots \\
\text { Program } g\end{array}$ & $W^{\prime}$ & $\cdots$ & $\cdots$ & $\cdots$ & $\cdots$ & $\cdots$ \\
\hline Threat 1 & $c_{g}$ & $W_{c_{g 1}}^{\prime \prime}$ & $r_{c_{g 1}}$ & $P_{c_{g 1}}^{1}$ & $\cdots$ & $P_{c_{g 1}}^{q}$ \\
\hline$\cdots$ & & $\cdots$ & $\cdots$ & $\cdots$ & $\cdots$ & . \\
\hline Threat $N_{c_{g}}$ & & $\ddot{W}_{c_{g N_{c g}}}^{\prime \prime}$ & $\begin{array}{l}\cdots \\
r_{c_{g N} N_{g}}\end{array}$ & $\ddot{P}_{c_{g N C_{g}}}^{1}$ & $\cdots$ & $P_{c_{g} N_{C_{g}}}^{q}$ \\
\hline \multirow[t]{2}{*}{ Total weighted threat $\left(C^{m}\right)$} & & & & $C^{1}$ & $\ldots$ & $C^{q}$ \\
\hline & $\begin{array}{l}\text { Program } \\
\text { weight }\end{array}$ & $\begin{array}{l}\text { Response } \\
\text { weight }\end{array}$ & $\begin{array}{l}\text { Risk-aversion } \\
\text { constant }\end{array}$ & Recipient 1 & $\cdots$ & Recipient $q$ \\
\hline \multicolumn{7}{|l|}{ Benefits } \\
\hline Program 1 & $W_{b_{1}}^{\prime}$ & & & & & \\
\hline Response 1 & & $W_{b_{11}}^{\prime \prime}$ & $r_{b_{11}}$ & $P_{b_{11}}^{1}$ & $\cdots$ & $P_{b_{11}}^{q}$ \\
\hline$\cdots$ & & $\cdots$ & $\cdots$ & $\cdots$ & $\cdots$ & $\cdots$ \\
\hline$\cdots$ & & $\cdots$ & $\cdots$ & $\cdots$ & $\cdots$ & $\cdots$ \\
\hline $\begin{array}{l}\text { Response } N_{b_{1}} \\
\ldots\end{array}$ & & $\begin{array}{l}W_{b_{1 N_{b_{1}}}^{\prime \prime}}^{\prime \prime} \\
\ldots\end{array}$ & $\begin{array}{l}r_{b_{1 N_{b_{1}}}} \\
\cdots\end{array}$ & $\begin{array}{l}P_{b_{1 N_{b_{1}}}}^{1} \\
\cdots\end{array}$ & $\begin{array}{l}\cdots \\
\cdots\end{array}$ & $\begin{array}{l}P_{b_{I_{b_{1}}}}^{q} \\
\cdots\end{array}$ \\
\hline Program $g$ & $W_{b}^{\prime}$ & $\cdots$ & $\cdots$ & $\cdots$ & $\cdots$ & . \\
\hline Response 1 & & $W_{b_{g 1}}^{\prime \prime}$ & $r_{b_{g 1}}$ & $P_{b_{g 1}}^{1}$ & $\cdots$ & $P_{b_{g 1}}^{q}$ \\
\hline$\cdots$ & & $\cdots$ & $\cdots$ & $\cdots$ & $\cdots$ & $\cdots$ \\
\hline $\begin{array}{l}\cdots \\
\text { Resnonse } N_{l}\end{array}$ & & $\cdots$ & $\cdots$ & $\dddot{\cdots}$ & $\cdots$ & $\dddot{\cdots}$ \\
\hline Response $N_{b_{g}}$ & & $W_{b_{g N} N_{g}}^{\prime \prime}$ & $r_{b_{g N} b_{g}}$ & $P_{b_{g N}{ }_{b g}}^{1}$ & $\cdots$ & $P_{b_{g N b_{g}}}^{q}$ \\
\hline Total weighted responses $\left(B^{m}\right)$ & & & & $B^{1}$ & $\cdots$ & $B^{4}$ \\
\hline Standard deviation $\left(S^{m}\right)$ & & & & $S^{1}$ & $\ldots$ & $S^{q}$ \\
\hline Allocation score $\left(A^{m}\right)$ & & & & $A^{1}$ & $\ldots$ & $A^{q}$ \\
\hline
\end{tabular}

$B^{m}=$ The total weighted responses of the $m$ th recipient

$S^{m}=$ The standard deviation of the $m$ th recipient

$V_{c}^{m}=$ The variance of the threats for the $m$ th recipient

$V_{b}^{m}=$ The variance of the responses for the $m$ th recipient

$W_{c_{i}}^{\prime}=$ The $i$ th program weight associated with the threats

$W_{b}^{\prime}=$ The $i$ th program weight associated with the responses

$\bar{W}_{c i j}^{\prime \prime}=$ The subjective weight of the $j$ th threat in the $i$ th program

$\bar{W}_{b_{i j}}^{\prime \prime}=$ The subjective weight of the $j$ th response in the $i$ th program 
$\hat{W}_{c_{i j}}^{\prime \prime}=$ The intrinsic weight of the $j$ th threat in the $i$ th program

$\hat{W}_{b_{i j}}^{\prime \prime}=$ The intrinsic weight of the $j$ th response in the $i$ th program

$W_{c i j}^{\prime \prime}=$ The overall weight of the $j$ th threat in the $i$ th program

$W_{b_{i j}}^{\prime \prime}=$ The overall weight of the $j$ th response in the $i$ th program

$P_{c_{i j}}^{m_{i j}}=$ The $m$ th probability of occurrence of the $j$ th threat in the $i$ th program

$P_{b_{i j}}^{m}=$ The $m$ th probability of occurrence of the $j$ th response in the $i$ th program

$r_{c_{i j}}=$ The risk-aversion constant of the $j$ th threat in the $i$ th program

$r_{b_{i j}}=$ The risk-aversion constant of the $j$ th response in the $i$ th program

$m=1,2, \ldots, q$

$i \quad=1,2, \ldots, g$

$q \quad=$ The number of recipients

$g \quad=$ The number of programs

and $j=1,2, \ldots, N_{c_{i}}$ for the threats where $N_{c_{i}}$ is the number of threats in the $i$ th program and $j=1$, $2, \ldots, N_{b_{i}}$ for the responses where $N_{b_{i}}$ is the number of responses in the $i$ th program, Slice calculates the allocation score $\left(A^{m}\right)$ as

$$
A^{m}=\left(\frac{C^{m}}{B^{m}}\right) S^{m}
$$

where

$$
\begin{aligned}
& C^{m}=\sum_{i=1}^{g} W_{c_{i}}^{\prime}\left(\sum_{j=1}^{N_{c_{i}}} W_{c_{i j}}^{\prime \prime}\left[-\frac{1}{r_{c_{i j}}} \ln \left(1-P_{c_{i j}}^{m}+P_{c_{i j}}^{m} e^{-r_{c_{i j}}}\right)\right]\right), \\
& B^{m}=\sum_{i=1}^{g} W_{b_{i}}^{\prime}\left(\sum_{j=1}^{N_{b_{i}}} W_{b_{i j}}^{\prime \prime}\left[-\frac{1}{r_{b_{i j}}} \ln \left(1-P_{b_{i j}}^{m}+P_{b_{i j}}^{m} e^{-r_{b_{i j}}}\right)\right]\right), \\
& S^{m}=\sqrt{V_{c}^{m}+V_{b}^{m}}, \\
& V_{c}^{m}=\sum_{i=1}^{g} W_{c_{i}}^{\prime} \sum_{j=1}^{N_{c_{i}}}\left[\left(-\frac{1}{r_{c_{i j}}} \ln \left(1-P_{c_{i j}}^{m}+P_{c_{i j}}^{m} e^{-r_{c_{i j}}}\right)-C^{m}\right)^{2} W_{c_{i j}}^{\prime \prime}\right], \\
& V_{b}^{m}=\sum_{i=1}^{g} W_{b_{i}}^{\prime} \sum_{j=1}^{N_{b_{i}}}\left[\left(-\frac{1}{r_{b_{i j}}} \ln \left(1-P_{b_{i j}}^{m}+P_{b_{i j}}^{m} e^{-r_{b_{i j}}}\right)-B^{m}\right)^{2} W_{b_{i j}}^{\prime \prime}\right], \\
& \sum_{i=1}^{g} W_{c_{i}}^{\prime}=1,
\end{aligned}
$$




$$
\begin{aligned}
& \sum_{i=1}^{g} W_{b_{i}}^{\prime}=1, \\
& \sum_{j=1}^{N_{c_{i}}} W_{c_{i j}}^{\prime \prime}=1, \\
& \sum_{j=1}^{N_{b_{i}}} W_{b_{i j}}^{\prime \prime}=1, \\
& 0 \leqslant P_{c_{i j}}^{m} \leqslant 1, \\
& 0 \leqslant P_{b_{i j}}^{m} \leqslant 1 .
\end{aligned}
$$

(9) Allocate funds according to the normalized allocation and population scores: Assuming that $T$ dollars are available for distribution among the states and territories, $D$ dollars are allocated in proportion to the normalized allocation scores, and the remaining $S$ dollars are allocated in proportion to the normalized population of the states and territories.

The recipients with larger allocation scores receive a larger percentage of the budgeted $D$ dollars while the recipients with smaller allocation scores receive a smaller percentage of the budget. First, the allocation scores are normalized so that the normalized allocation scores $\left(\bar{A}^{m}\right)$ add up to one $\left(\sum_{m=1}^{q} \bar{A}^{m}=1\right)$. To ensure that proportionality is conserved, Slice uses $\bar{A}^{m}=\frac{A^{m}}{\sum_{m=1}^{q} A^{m}}$ to develop a normalized vector for $\bar{A}^{m}$ where $0<\bar{A}^{m}<1$. To determine the optimal proportions of $D$ and $S$, an allocation table is constructed based on varying percentages for $D$ and $S$ with a $1 \%$ increment. In the allocation table, in one extreme $0 \%$ of the budget is allocated to $S$ and $100 \%$ to $D$, and on the other extreme $100 \%$ of the budget is allocated to $S$ and $0 \%$ to $D$. The root mean squared error (RMSE) of the alternative proportions is used to determine the optimal proportions for $D$ and $S$.

Next, the allocation table is represented by matrix $\left(T_{m k}\right)$. Each row of the matrix expresses the total allocation dollars for recipient $m$ relative to the $h$ allocation proportions under consideration. Let $d_{k}$ be the weight of $D$ and therefore $s_{k}=1-d_{k}$ be the weight of $S$. Given $d_{k}=d_{1}, d_{2}, \ldots, d_{h}, \Delta d=d_{k+1}-d_{k}$ is defined as the increment used to develop the $h$ allocation proportions. For example, with $\Delta d=0.01$, allocation proportions such as $d=\{0.00,0.01, \ldots$, $1.00\}$ are considered while $s=\{1.00,0.99, \ldots, 0.00\}$. For each $d_{k}$, recipient $m$ receives a total of $T_{m k}=D_{m k}+S_{m k}$ where $D_{m k}$ dollars is allocated based on the adjusted allocation scores and the remaining $S_{m k}$ dollars are allocated according to the population of the states and territories.

The RMSE of the alternative proportions are used to determine the optimal proportions of $D$ and $S$. RMSE is the square root of the deviation of the allocation dollars $\left(T_{m k}\right)$ from the ideal amount $\left(\max T_{k}\right)$ across all $m$ recipients for all $h$ allocation proportions under consideration

$$
\mathrm{RMSE}_{k}=\sqrt{\frac{\sum_{m=1}^{q}\left(T_{m k}-\max T_{k}\right)^{2}}{q} .}
$$

The optimal proportions of $D$ and $S$ are used in the allocation procedure described earlier to distribute the total $T$ dollars made available by DHS for the state homeland security grant program (SHGP). 


\section{Pilot study}

A pilot study was conducted to allocate $\$ 2,518,763,121$ to the states and territories based on their need for homeland security. Eight DMs, all experts in national security, participated in this study. Four DMs had an average of 6.2 years of homeland security work and/or committee experience. All were elected officials with graduate degrees in law and humanities. Two DMs were consultants with an average of 12.5 years of homeland security experience and doctoral degrees. The last two DMs were homeland security employees for a large city in the Northeast, both with an average of 8.4 years of homeland security experience and graduate degrees. Initially, the DMs discussed the six HSGP programs (SHSP, UASI, LETPP, CCP, EMPG, and MMRS) and the 58 states and territories. After careful consideration of the states and territories, the DMs agreed to use Slice to determine funding for the 50 states, the District of Columbia, and Puerto Rico. There was a consensus that the Virgin Islands, American Samoa, Guam, and the Northern Mariana Islands each should receive $0.2 \%(\$ 5,037,526)$ of the budget and that the Republic of the Marshall Islands and the Federated States of Micronesia each should receive $0.002 \%$ $(\$ 50,375)$ of the budget. Using this formula, $\$ 20,250,855$ was allocated to the six territories. The remaining $\$ 2,498,512,266$ was reserved for the 50 states, the District of Columbia, and Puerto Rico.

Next, the DMs developed a set of threats and responses related to the six HSGP programs by participating in a series of brainstorming sessions. For example, SHSP provides planning, equipment, training, exercise, and management and administrative funding to emergency prevention, preparedness, and response personnel in states and territories. An example of a threat for this program is the threat of an attack on nuclear power plants. An example of a response is the responsiveness of the military or National Guard. A state with a high probability of attack on their nuclear power plants should receive more funding while a state with a high level of military and National Guard presence should receive less funding. After several brainstorming sessions, our DMs were able to reach a fairly clear consensus on 56 threats and responses associated with the six assistance programs (see Table 2).

Next, the DMs assessed the relative weight associated with each program. The importance weighting of the assistance programs were captured with the AHP and Expert Choice software (Expert Choice, 2004). Once the initial weights were determined, the group received anonymous feedback that included the individual and group weights for the six programs. The group members were asked to reconsider their judgments to achieve some consistency and consensus. Using this feedback mechanism, a consensus of the weights for each of the threats and the responses in each program was obtained (see Table 3). Similarly, the DMs used Expert Choice to derive the initial weights for each of the threats and responses. The group received anonymous feedback that included the individual and group weights for the threats and responses. Some DMs changed their subjective weights after reviewing the group and individual averages.

Next, the DMs developed a set of probabilities of occurrence for each threat and response associated with the state or territory under consideration. Then, an independent group of experts estimated a probability of occurrence for each threat and response for the country as a whole. The state or territory probabilities of occurrence were calibrated against these independent probability estimates. Table 4 represents a selected group of states with their calibrated probabilities of occurrence for each of the threats and responses. For example, there is a $0.9 \%$ probability of 
Table 2

The threats and responses used in the pilot study

\begin{tabular}{|c|c|c|}
\hline Program & Threat & Description \\
\hline \multirow{6}{*}{ SHSP } & NPP & Threat of attack on nuclear power plants \\
\hline & $\mathrm{CHP}$ & Threat of attack on chemical plants \\
\hline & MLB & Threat of attack on military bases \\
\hline & SFB & Threat of attack on state/federal centers/buildings \\
\hline & NMP & Threat of attack on national monuments/parklands \\
\hline & AST & Threat of attack on airports/seaports/train stations \\
\hline \multirow[t]{3}{*}{ UASI } & FIN & Threat of attack on financial institutions \\
\hline & SKY & Threat of attack on skyscrapers \\
\hline & TRS & Threat of attack on mass transit \\
\hline \multirow[t]{5}{*}{ LETPP } & ARN & Threat of attack on public arenas \\
\hline & WTR & Threat of attack on water supply \\
\hline & CIT & Threat of credit card fraud/identity theft \\
\hline & CML & Threat of counterfeiting money/money laundering \\
\hline & REC & Threat of accessing law enforcements data/records electronically \\
\hline \multirow{4}{*}{$\mathrm{CCP}$} & NDS & Threat of natural disaster \\
\hline & CYB & Threat of cyber attack \\
\hline & LCS & Threat of attack on local communications systems \\
\hline & CRM & Threat of hike in crime rate \\
\hline \multirow[t]{4}{*}{ EMPG } & BRT & Threat of attack on bridges and tunnels \\
\hline & PWG & Threat of attack on power grid \\
\hline & ORF & Threat of attacks on oil refineries \\
\hline & $\mathrm{BRD}$ & Threat of breach of security in international borders and coastlines \\
\hline \multirow{4}{*}{ MMRS } & $\mathrm{CHM}$ & Threat of chemical attack \\
\hline & $\mathrm{BIO}$ & Threat of biological attack \\
\hline & EPD & Threat of pandemic/global epidemic \\
\hline & RAD & Threat of radiological attack \\
\hline Program & Response & Description \\
\hline \multirow[t]{6}{*}{ SHSP } & MNG & Responsiveness of military and national guards \\
\hline & CBR & $\begin{array}{l}\text { Responsiveness of chemical, biological, radiological/nuclear, explosive detection/ } \\
\text { decontamination facilities }\end{array}$ \\
\hline & MRP & Responsiveness of nuclear meltdown response plans \\
\hline & IPD & Responsiveness of information analysis and infrastructure protections directorates \\
\hline & CST & Responsiveness of cyber security training programs \\
\hline & SEC & Responsiveness of airport/seaport/train station security \\
\hline \multirow[t]{5}{*}{ UASI } & DRP & Responsiveness of disaster recovery plans \\
\hline & SEQ & Responsiveness of security enhancement equipment \\
\hline & STA & Responsiveness of adequate surface transportation alternatives \\
\hline & MTS & Responsiveness of mass transit security \\
\hline & CRP & Responsiveness of financial institution crisis response program \\
\hline \multirow[t]{4}{*}{ LETPP } & LEP & Responsiveness of law enforcement personnel \\
\hline & ICS & Responsiveness of interoperable communication systems \\
\hline & EPP & Responsiveness of training programs for emergency preparedness \\
\hline & SCT & Responsiveness of surveillance and counter-surveillance technology \\
\hline \multirow[t]{2}{*}{$\mathrm{CCP}$} & ERT & Responsiveness of community emergency response teams \\
\hline & MVO & Responsiveness of multiple volunteer organizations \\
\hline
\end{tabular}


Table 2. (Contd.)

\begin{tabular}{lll}
\hline Program & Response & Description \\
\hline & NWP & Responsiveness of neighborhood watch programs \\
& EDT & Responsiveness of education and training for the community \\
& FMC & Responsiveness of fire corps and medical reserve corps \\
EMPG & CCC & Responsiveness of active state citizens corps councils \\
& EMS & Responsiveness of emergency management systems \\
& IMS & Responsiveness of national incident management systems \\
& RES & Responsiveness of first responders \\
MMRS & REP & Responsiveness of coordinated regional evacuation plan \\
& MMR & Responsiveness of metropolitan medical response systems jurisdictions \\
& CPA & Responsiveness of chemical production plant compliance agencies \\
& TRF & Responsiveness of treatment facilities \\
& EMT & Responsiveness of local emergency medical technicians and paramedics \\
& DVS & Responsiveness of drug/vaccine stockpiles \\
\hline
\end{tabular}

Table 3

Weights and the risk-aversion constants used in the pilot study program

\begin{tabular}{llllll}
\hline Program (program weight) & Threat & Initial weight & Intrinsic weight & Overall weight & Risk-aversion constant \\
\hline SHSP $(0.350)$ & NPP & 0.300 & 0.411 & 0.594 & 1.801 \\
& CHP & 0.200 & 0.163 & 0.157 & 3.281 \\
& MLB & 0.100 & 0.141 & 0.068 & 0.822 \\
& SFB & 0.200 & 0.090 & 0.086 & 6.922 \\
& NMP & 0.100 & 0.048 & 0.023 & 0.403 \\
AST & 0.100 & 0.147 & 0.071 & 1.279 \\
UASI $(0.300)$ & FIN & 0.300 & 0.300 & 0.269 & 1.801 \\
& SKY & 0.200 & 0.351 & 0.210 & 0.822 \\
LETPP $(0.150)$ & TRS & 0.500 & 0.349 & 0.522 & 6.922 \\
& ARN & 0.400 & 0.273 & 0.515 & 6.922 \\
& WTR & 0.250 & 0.103 & 0.122 & 4.551 \\
& CIT & 0.100 & 0.068 & 0.032 & 1.279 \\
CCP $(0.050)$ & CML & 0.100 & 0.261 & 0.123 & 0.403 \\
& REC & 0.150 & 0.294 & 0.208 & 1.801 \\
& NDS & 0.500 & 0.105 & 0.270 & 6.922 \\
EMPG $(0.100)$ & CYB & 0.150 & 0.436 & 0.336 & 1.279 \\
& LCS & 0.150 & 0.302 & 0.233 & 0.822 \\
& CRM & 0.200 & 0.157 & 0.162 & 1.801 \\
& BRT & 0.500 & 0.134 & 0.321 & 6.922 \\
& PWG & 0.200 & 0.153 & 0.146 & 0.822 \\
MMRS $(0.050)$ & ORF & 0.200 & 0.398 & 0.382 & 0.403 \\
& BRD & 0.100 & 0.315 & 0.151 & 0.403 \\
& CHM & 0.400 & 0.277 & 0.403 & 6.922 \\
& BIO & 0.300 & 0.343 & 0.374 & 3.281 \\
& EPD & 0.200 & 0.235 & 0.171 & 1.801 \\
& RAD & 0.100 & 0.144 & 0.052 & 0.822 \\
\hline
\end{tabular}

(C) 2007 The Authors.

Journal compilation (C) International Federation of Operational Research Societies 2007 
Table 3. (Contd.)

\begin{tabular}{lllllc}
\hline Program (program weight) & Response & Initial weight & Intrinsic weight & Overall weight & Risk-aversion constant \\
\hline SHSP $(0.350)$ & MNG & 0.350 & 0.082 & 0.213 & 6.922 \\
& CBR & 0.250 & 0.073 & 0.135 & 4.551 \\
& MRP & 0.100 & 0.492 & 0.364 & 1.801 \\
& IPD & 0.050 & 0.105 & 0.039 & 0.822 \\
CST & 0.050 & 0.108 & 0.040 & 0.403 \\
UASI $(0.300)$ & SEC & 0.200 & 0.141 & 0.209 & 3.281 \\
& DRP & 0.350 & 0.063 & 0.136 & 13.863 \\
& SEQ & 0.150 & 0.088 & 0.082 & 2.438 \\
STA & 0.100 & 0.469 & 0.290 & 1.279 \\
LETPP $(0.150)$ & MTS & 0.250 & 0.226 & 0.350 & 3.281 \\
& CRP & 0.150 & 0.154 & 0.143 & 2.438 \\
& LEP & 0.400 & 0.169 & 0.305 & 6.922 \\
CCP $(0.050)$ & ICS & 0.300 & 0.068 & 0.092 & 4.551 \\
& EPP & 0.200 & 0.571 & 0.516 & 1.801 \\
& SCT & 0.100 & 0.192 & 0.087 & 1.279 \\
& ERT & 0.350 & 0.105 & 0.259 & 4.551 \\
& MVO & 0.250 & 0.103 & 0.182 & 3.281 \\
& NWP & 0.100 & 0.115 & 0.081 & 0.822 \\
& EDT & 0.050 & 0.243 & 0.085 & 0.403 \\
EMPG $(0.100)$ & FMC & 0.150 & 0.252 & 0.266 & 2.438 \\
& CCC & 0.100 & 0.181 & 0.127 & 1.801 \\
& EMS & 0.350 & 0.412 & 0.540 & 6.922 \\
MMRS $(0.050)$ & IMS & 0.300 & 0.194 & 0.218 & 4.551 \\
& RES & 0.250 & 0.168 & 0.157 & 1.279 \\
& REP & 0.100 & 0.227 & 0.085 & 0.403 \\
MMR & 0.350 & 0.097 & 0.195 & 4.551 \\
& CPA & 0.250 & 0.166 & 0.239 & 3.281 \\
& TRF & 0.150 & 0.200 & 0.172 & 2.438 \\
& EMT & 0.150 & 0.301 & 0.259 & 1.801 \\
& DVS & 0.100 & 0.235 & 0.135 & 0.822 \\
\hline
\end{tabular}

attack on the nuclear power plants in the state of Alabama while there is a $0.4 \%$ probability of attack on the nuclear power plants in the state of Arizona. These probabilities are fairly small because they were calibrated with the probability of each event for the country as a whole.

Based on the entropy concept, the intrinsic weight of each threat and response was calculated according to the contrast intensity of the calibrated probabilities of occurrence. The overall weight for each threat and response was then calculated by multiplying the initial weight times the intrinsic weight. In addition, a risk-aversion constant was derived for each of the threats and the responses. The certainty equivalence concept was used to determine the risk-aversion constants. Each DM was asked to estimate his or her certainty equivalence for each threat and the response. The group average certainty equivalences were used to determine the risk-aversion constant of each threat and response in the model (see Table 3).

Finally, Table 5 presents the allocation dollars to the states and territories. These funds are allocated based on a $28 \%$ weight for the allocation scores and a $72 \%$ weight for the population 
Table 4

Calibrated probabilities of occurrence (for selected states and District of Columbia) used in the pilot study

\begin{tabular}{|c|c|c|c|c|c|c|c|c|c|c|c|c|}
\hline & $\mathrm{AL}$ & $\mathrm{AZ}$ & $\mathrm{CA}$ & $\mathrm{DC}$ & $\mathrm{DE}$ & FL & KY & NY & $\mathrm{OH}$ & TX & WI & WY \\
\hline \multicolumn{13}{|l|}{ Threat } \\
\hline NPP & 0.009 & 0.004 & 0.011 & 0.000 & 0.000 & 0.015 & 0.000 & 0.015 & 0.009 & 0.011 & 0.009 & 0.000 \\
\hline CHP & 0.002 & 0.006 & 0.016 & 0.004 & 0.004 & 0.014 & 0.006 & 0.010 & 0.014 & 0.019 & 0.006 & 0.002 \\
\hline MLB & 0.010 & 0.010 & 0.027 & 0.017 & 0.003 & 0.020 & 0.013 & 0.010 & 0.003 & 0.020 & 0.003 & 0.003 \\
\hline SFB & 0.004 & 0.008 & 0.006 & 0.016 & 0.002 & 0.006 & 0.008 & 0.006 & 0.004 & 0.008 & 0.008 & 0.002 \\
\hline NMP & 0.006 & 0.008 & 0.012 & 0.012 & 0.004 & 0.009 & 0.006 & 0.010 & 0.010 & 0.009 & 0.010 & 0.005 \\
\hline AST & 0.002 & 0.004 & 0.018 & 0.016 & 0.004 & 0.012 & 0.008 & 0.008 & 0.006 & 0.010 & 0.006 & 0.002 \\
\hline FIN & 0.002 & 0.010 & 0.015 & 0.013 & 0.008 & 0.013 & 0.008 & 0.017 & 0.008 & 0.015 & 0.008 & 0.002 \\
\hline SKY & 0.003 & 0.006 & 0.011 & 0.014 & 0.005 & 0.009 & 0.006 & 0.014 & 0.008 & 0.011 & 0.005 & 0.002 \\
\hline TRS & 0.007 & 0.007 & 0.019 & 0.019 & 0.005 & 0.014 & 0.007 & 0.021 & 0.012 & 0.016 & 0.009 & 0.002 \\
\hline ARN & 0.005 & 0.012 & 0.012 & 0.012 & 0.002 & 0.017 & 0.010 & 0.017 & 0.007 & 0.020 & 0.007 & 0.002 \\
\hline WTR & 0.008 & 0.008 & 0.017 & 0.013 & 0.004 & 0.013 & 0.021 & 0.017 & 0.013 & 0.017 & 0.008 & 0.004 \\
\hline CIT & 0.022 & 0.022 & 0.037 & 0.015 & 0.015 & 0.029 & 0.022 & 0.029 & 0.022 & 0.037 & 0.022 & 0.007 \\
\hline CML & 0.016 & 0.016 & 0.032 & 0.020 & 0.028 & 0.024 & 0.008 & 0.036 & 0.024 & 0.032 & 0.012 & 0.004 \\
\hline REC & 0.016 & 0.020 & 0.032 & 0.036 & 0.008 & 0.024 & 0.012 & 0.036 & 0.004 & 0.028 & 0.004 & 0.004 \\
\hline NDS & 0.026 & 0.013 & 0.035 & 0.022 & 0.013 & 0.040 & 0.018 & 0.022 & 0.013 & 0.035 & 0.013 & 0.004 \\
\hline CYB & 0.007 & 0.007 & 0.063 & 0.063 & 0.007 & 0.063 & 0.007 & 0.063 & 0.042 & 0.056 & 0.014 & 0.014 \\
\hline LCS & 0.010 & 0.007 & 0.030 & 0.010 & 0.003 & 0.026 & 0.010 & 0.026 & 0.020 & 0.030 & 0.010 & 0.003 \\
\hline CRM & 0.016 & 0.022 & 0.025 & 0.006 & 0.025 & 0.028 & 0.009 & 0.019 & 0.009 & 0.022 & 0.006 & 0.009 \\
\hline BRT & 0.005 & 0.005 & 0.018 & 0.003 & 0.003 & 0.008 & 0.003 & 0.010 & 0.010 & 0.023 & 0.005 & 0.003 \\
\hline PWG & 0.008 & 0.006 & 0.019 & 0.002 & 0.002 & 0.014 & 0.004 & 0.008 & 0.012 & 0.017 & 0.017 & 0.004 \\
\hline ORF & 0.019 & 0.000 & 0.034 & 0.000 & 0.004 & 0.000 & 0.015 & 0.000 & 0.023 & 0.038 & 0.004 & 0.019 \\
\hline BRD & 0.000 & 0.019 & 0.022 & 0.000 & 0.011 & 0.025 & 0.000 & 0.022 & 0.003 & 0.025 & 0.003 & 0.000 \\
\hline $\mathrm{CHM}$ & 0.003 & 0.003 & 0.009 & 0.010 & 0.004 & 0.009 & 0.003 & 0.012 & 0.007 & 0.009 & 0.003 & 0.003 \\
\hline $\mathrm{BIO}$ & 0.002 & 0.001 & 0.006 & 0.007 & & & & & 0.003 & 0.003 & 0.002 & 0.001 \\
\hline EPD & 0.003 & 0.005 & 0.013 & 0.010 & 0.007 & 0.013 & 0.005 & 0.012 & 0.005 & 0.012 & 0.003 & 0.003 \\
\hline RAD & 0.002 & 0.002 & 0.003 & 0.005 & 0.003 & 0.003 & 0.002 & 0.005 & 0.003 & 0.005 & 0.002 & 0.002 \\
\hline \multicolumn{13}{|c|}{ Response } \\
\hline MNG & 0.015 & 0.015 & 0.040 & 0.015 & 0.010 & 0.035 & 0.015 & 0.020 & 0.010 & 0.035 & 0.010 & 0.010 \\
\hline CBR & 0.004 & 0.005 & 0.012 & 0.005 & 0.007 & 0.009 & 0.007 & 0.011 & 0.007 & 0.011 & 0.007 & 0.005 \\
\hline MRP & 0.025 & 0.017 & 0.025 & 0.000 & 0.000 & 0.034 & 0.000 & 0.050 & 0.025 & 0.025 & 0.025 & 0.000 \\
\hline IPD & 0.009 & 0.009 & 0.000 & 0.016 & 0.020 & 0.004 & 0.009 & 0.004 & 0.004 & 0.002 & 0.009 & 0.020 \\
\hline CST & 0.005 & 0.011 & 0.014 & 0.012 & 0.004 & 0.007 & 0.002 & 0.016 & 0.005 & 0.012 & 0.007 & 0.002 \\
\hline SEC & 0.002 & 0.006 & 0.006 & 0.002 & 0.002 & 0.010 & 0.002 & 0.006 & 0.004 & 0.014 & 0.002 & 0.002 \\
\hline DRP & 0.004 & 0.004 & 0.015 & 0.007 & 0.009 & 0.015 & 0.007 & 0.015 & 0.007 & 0.015 & 0.007 & 0.013 \\
\hline SEQ & 0.005 & 0.006 & 0.003 & 0.006 & 0.012 & 0.001 & 0.005 & 0.003 & 0.003 & 0.001 & 0.005 & 0.012 \\
\hline STA & 0.000 & 0.003 & 0.015 & 0.018 & 0.010 & 0.010 & 0.003 & 0.015 & 0.005 & 0.005 & 0.000 & 0.010 \\
\hline MTS & 0.001 & 0.005 & 0.011 & 0.008 & 0.008 & 0.009 & 0.001 & 0.008 & 0.007 & 0.009 & 0.004 & 0.001 \\
\hline CRP & 0.007 & 0.003 & 0.011 & 0.002 & 0.002 & 0.011 & 0.010 & 0.008 & 0.010 & 0.015 & 0.011 & 0.003 \\
\hline LEP & 0.008 & 0.008 & 0.013 & 0.016 & 0.016 & 0.016 & 0.011 & 0.019 & 0.013 & 0.019 & 0.008 & 0.005 \\
\hline ICS & 0.009 & 0.011 & 0.017 & 0.014 & 0.020 & 0.014 & 0.009 & 0.014 & 0.014 & 0.017 & 0.011 & 0.011 \\
\hline EPP & 0.029 & 0.010 & 0.039 & 0.039 & 0.010 & 0.039 & 0.010 & 0.058 & 0.019 & 0.029 & 0.019 & 0.010 \\
\hline SCT & 0.005 & 0.003 & 0.001 & 0.007 & 0.007 & 0.002 & 0.005 & 0.002 & 0.003 & 0.001 & 0.006 & 0.007 \\
\hline ERT & 0.006 & 0.006 & 0.013 & 0.003 & 0.004 & 0.013 & 0.012 & 0.013 & 0.013 & 0.012 & 0.007 & 0.003 \\
\hline MVO & 0.004 & 0.009 & 0.017 & 0.007 & 0.007 & 0.017 & 0.011 & 0.017 & 0.017 & 0.017 & 0.006 & 0.004 \\
\hline NWP & 0.014 & 0.016 & 0.002 & 0.018 & 0.014 & 0.004 & 0.014 & 0.004 & 0.008 & 0.002 & 0.014 & 0.018 \\
\hline
\end{tabular}

(C) 2007 The Authors.

Journal compilation (C) International Federation of Operational Research Societies 2007 
Table 4. (Contd.)

\begin{tabular}{lllllllllllll}
\hline & AL & AZ & CA & DC & DE & FL & KY & NY & OH & TX & WI & WY \\
\hline EDT & 0.007 & 0.005 & 0.017 & 0.002 & 0.002 & 0.002 & 0.005 & 0.015 & 0.020 & 0.010 & 0.002 & 0.002 \\
FMC & 0.005 & 0.005 & 0.015 & 0.002 & 0.003 & 0.010 & 0.007 & 0.010 & 0.010 & 0.015 & 0.008 & 0.002 \\
CCC & 0.006 & 0.007 & 0.015 & 0.002 & 0.002 & 0.006 & 0.006 & 0.009 & 0.011 & 0.009 & 0.002 & 0.002 \\
EMS & 0.004 & 0.007 & 0.021 & 0.025 & 0.004 & 0.007 & 0.004 & 0.028 & 0.004 & 0.018 & 0.004 & 0.004 \\
IMS & 0.003 & 0.003 & 0.001 & 0.006 & 0.006 & 0.001 & 0.003 & 0.001 & 0.001 & 0.001 & 0.003 & 0.007 \\
RES & 0.012 & 0.012 & 0.006 & 0.006 & 0.001 & 0.004 & 0.012 & 0.001 & 0.012 & 0.012 & 0.012 & 0.009 \\
REP & 0.008 & 0.008 & 0.002 & 0.016 & 0.016 & 0.002 & 0.008 & 0.002 & 0.004 & 0.002 & 0.008 & 0.008 \\
MMR & 0.003 & 0.005 & 0.012 & 0.013 & 0.008 & 0.010 & 0.007 & 0.013 & 0.008 & 0.012 & 0.007 & 0.005 \\
CPA & 0.001 & 0.004 & 0.011 & 0.004 & 0.004 & 0.002 & 0.004 & 0.009 & 0.006 & 0.010 & 0.006 & 0.002 \\
TRF & 0.008 & 0.008 & 0.030 & 0.004 & 0.004 & 0.019 & 0.008 & 0.019 & 0.015 & 0.034 & 0.011 & 0.004 \\
EMT & 0.009 & 0.009 & 0.030 & 0.039 & 0.004 & 0.022 & 0.004 & 0.039 & 0.026 & 0.022 & 0.004 & 0.004 \\
DVS & 0.004 & 0.004 & 0.016 & 0.016 & 0.004 & 0.014 & 0.002 & 0.014 & 0.006 & 0.012 & 0.002 & 0.008 \\
\hline
\end{tabular}

Table 5

Allocation scores and dollars for a $28-72 \%$ split model

State $C^{m} \quad B^{m} \quad S^{m} \quad A^{m} \quad \bar{A}^{m} \quad$ Population Normalized Allocation $\$$ Population $\$$ Total $\$$
population

\begin{tabular}{|c|c|c|c|c|c|c|c|c|c|c|}
\hline $\mathrm{AL}$ & 0.0031 & 0.0037 & 0.0059 & 0.0049 & 0.0166 & $4,447,100$ & 0.0156 & $11,618,741$ & $28,047,547$ & $39,666,288$ \\
\hline $\mathrm{AK}$ & 0.0021 & 0.0026 & 0.0055 & 0.0043 & 0.0145 & 626,932 & 0.0022 & $10,139,272$ & $3,954,016$ & $14,093,288$ \\
\hline AZ & 0.0030 & 0.0029 & 0.0039 & 0.0040 & 0.0134 & $5,130,632$ & 0.0180 & $9,393,170$ & $32,358,536$ & $41,751,706$ \\
\hline AR & 0.0022 & 0.0023 & 0.0040 & 0.0037 & 0.0124 & $2,673,400$ & 0.0094 & $8,690,032$ & $16,860,946$ & $25,550,978$ \\
\hline CA & 0.0076 & 0.0062 & 0.0093 & 0.0114 & 0.0384 & $33,871,648$ & 0.1188 & $26,852,987$ & $213,626,105$ & $240,479,092$ \\
\hline $\mathrm{CO}$ & 0.0026 & 0.0018 & 0.0036 & 0.0052 & 0.0175 & $4,301,261$ & 0.0151 & $12,262,508$ & $27,127,751$ & $39,390,259$ \\
\hline CT & 0.0030 & 0.0030 & 0.0046 & 0.0047 & 0.0157 & $3,405,565$ & 0.0119 & $11,007,597$ & $21,478,659$ & $32,486,257$ \\
\hline DE & 0.0020 & 0.0023 & 0.0043 & 0.0037 & 0.0125 & 783,600 & 0.0027 & $8,737,478$ & $4,942,110$ & $13,679,588$ \\
\hline DC & 0.0042 & 0.0043 & 0.0082 & 0.0081 & 0.0272 & 572,059 & 0.0020 & $19,022,757$ & $3,607,936$ & $22,630,693$ \\
\hline FL & 0.0061 & 0.0060 & 0.0083 & 0.0085 & 0.0285 & $15,982,378$ & 0.0560 & $19,934,809$ & $100,799,736$ & $120,734,544$ \\
\hline GA & 0.0039 & 0.0036 & 0.0048 & 0.0051 & 0.0173 & 8,18 & 0.0287 & 12 & 51,6 & 16,741 \\
\hline HI & 0.0027 & 0.0015 & 0.0049 & 0.0092 & 0.0309 & $1,211,537$ & 0.00 & 21, & 79 & $29,259,807$ \\
\hline ID & 0.0011 & 0.0016 & 0.0032 & 0.0022 & 0.0073 & $1,293,953$ & 0.0045 & 749 & 8, & 6,620 \\
\hline IL & 0.0060 & 0.0076 & 0.0125 & 0.0099 & 0.0333 & $12,419,293$ & 0.0435 & $23,319,862$ & $78,327,609$ & $101,647,470$ \\
\hline IN & 0.0029 & 0.0019 & 0.0040 & 0.0061 & 0.0204 & $6,080,485$ & 0.0213 & $14,240,058$ & $38,349,192$ & $52,589,250$ \\
\hline IA & 0.0019 & 0.0027 & 0.0036 & 0.0026 & 0.0086 & $2,926,324$ & 0.0103 & $6,019,915$ & $18,456,120$ & $24,476,035$ \\
\hline KS & 0.0025 & 0.0027 & 0.0044 & 0.0041 & 0.0139 & $2,688,418$ & 0.0094 & $9,757,271$ & $16,955,664$ & $26,712,934$ \\
\hline KY & 0.0026 & 0.0017 & 0.0035 & 0.0053 & 0.0177 & $4,041,769$ & 0.0142 & $12,364,362$ & $25,491,153$ & $37,855,515$ \\
\hline LA & 0.0047 & 0.0040 & 0.0073 & 0.0085 & 0.0287 & $4,468,976$ & 0.0157 & $20,044,947$ & $28,185,518$ & $48,230,465$ \\
\hline ME & 0.0012 & 0.0015 & 0.0031 & 0.0025 & 0.0084 & $1,274,923$ & 0.0045 & $5,870,062$ & $8,040,850$ & $13,910,912$ \\
\hline MD & 0.0043 & 0.0040 & 0.0058 & 0.0062 & 0.0210 & $5,296,486$ & 0.0186 & $14,680,307$ & $33,404,565$ & $48,084,872$ \\
\hline MA & 0.0042 & 0.0038 & 0.0055 & 0.0061 & 0.0206 & $6,349,097$ & 0.0223 & $14,445,976$ & $40,043,309$ & $54,489,285$ \\
\hline MI & 0.0043 & 0.0037 & 0.0053 & 0.0062 & 0.0210 & $9,938,444$ & 0.0348 & $14,674,964$ & $62,681,068$ & $77,356,033$ \\
\hline $\mathrm{MN}$ & 0.0036 & 0.0033 & 0.0051 & 0.0055 & 0.0186 & $4,919,479$ & 0.0172 & $13,001,710$ & $31,026,809$ & $44,028,518$ \\
\hline MS & 0.0033 & 0.0027 & 0.0051 & 0.0062 & 0.0208 & $2,844,658$ & 0.0100 & $14,557,932$ & $17,941,058$ & $32,498,990$ \\
\hline MO & 0.0031 & 0.0027 & 0.0039 & 0.0046 & 0.0155 & $5,595,211$ & 0.0196 & $10,808,720$ & $35,288,603$ & $46,097,323$ \\
\hline MT & 0.0015 & 0.0016 & 0.0036 & 0.0034 & 0.0113 & 902,195 & 0.0032 & $7,890,283$ & $5,690,080$ & $13,580,364$ \\
\hline NE & 0.0022 & 0.0028 & 0.0046 & 0.0036 & 0.0120 & $1,711,263$ & 0.0060 & $8,367,909$ & $10,792,816$ & $19,160,724$ \\
\hline NV & 0.0031 & 0.0018 & 0.0066 & 0.0114 & 0.0383 & $1,998,257$ & 0.0070 & $26,827,605$ & $12,602,867$ & $39,430,472$ \\
\hline NH & 0.0021 & 0.0031 & 0.0041 & 0.0028 & 0.0094 & 5,786 & 0.0043 &, 714 & $7,794,016$ & $14,341,729$ \\
\hline
\end{tabular}


Table 5. (Contd.)

\begin{tabular}{|c|c|c|c|c|c|c|c|c|c|c|}
\hline State & $C^{m}$ & $B^{m}$ & $S^{m}$ & $A^{m}$ & $\bar{A}^{m}$ & Population & $\begin{array}{l}\text { Normalized } \\
\text { population }\end{array}$ & Allocation \$ & Population \$ & Total \$ \\
\hline $\mathrm{NJ}$ & 0.0065 & 0.0054 & 0.0083 & 0.0100 & 0.0338 & $8,414,350$ & 0.0295 & $23,622,581$ & $53,068,714$ & $76,691,295$ \\
\hline NM & 0.0023 & 0.0012 & 0.0047 & 0.0088 & 0.0298 & $1,819,046$ & 0.0064 & $20,814,128$ & $11,472,595$ & $32,286,724$ \\
\hline NY & 0.0066 & 0.0081 & 0.0114 & 0.0092 & 0.0310 & $18,976,457$ & 0.0665 & $21,691,381$ & $119,683,181$ & $141,374,562$ \\
\hline $\mathrm{NC}$ & 0.0038 & 0.0043 & 0.0066 & 0.0058 & 0.0196 & $8,049,313$ & 0.0282 & $13,732,842$ & $50,766,452$ & $64,499,294$ \\
\hline ND & 0.0013 & 0.0022 & 0.0036 & 0.0020 & 0.0069 & 642,200 & 0.0023 & $4,804,615$ & $4,050,310$ & $8,854,925$ \\
\hline $\mathrm{OH}$ & 0.0044 & 0.0041 & 0.0063 & 0.0068 & 0.0227 & $11,353,140$ & 0.0398 & $15,909,507$ & $71,603,457$ & $87,512,963$ \\
\hline OK & 0.0029 & 0.0026 & 0.0051 & 0.0058 & 0.0196 & $3,450,654$ & 0.0121 & $13,723,642$ & $21,763,032$ & $35,486,674$ \\
\hline OR & 0.0025 & 0.0015 & 0.0032 & 0.0051 & 0.0173 & $3,421,399$ & 0.0120 & $12,106,276$ & $21,578,523$ & $33,684,799$ \\
\hline PA & 0.0062 & 0.0072 & 0.0106 & 0.0091 & 0.0306 & $12,281,054$ & 0.0431 & $21,385,496$ & $77,455,745$ & $98,841,241$ \\
\hline RI & 0.0014 & 0.0027 & 0.0045 & 0.0024 & 0.0080 & $1,048,319$ & 0.0037 & $5,595,958$ & ,674 & 7,632 \\
\hline $\mathrm{SC}$ & 0.0038 & 0.0048 & 0.0083 & 0.0066 & 0.0222 & $4,012,012$ & 0.0141 & 15 & 25,3 & 40,8 \\
\hline SD & 0.0009 & 0.0035 & 0.0186 & 0.0048 & 0.0161 & 754,844 & 0.0026 & 1,600 & $4,760,748$ & 2,348 \\
\hline $\mathrm{TN}$ & 0.0033 & 0.0036 & 0.0048 & 0.0045 & 0.0152 & $5,689,283$ & 0.0199 & $10,613,624$ & $35,881,908$ & $46,495,532$ \\
\hline $\mathrm{TX}$ & 0.0074 & 0.0054 & 0.0089 & 0.0122 & 0.0411 & $20,851,820$ & 0.0731 & $28,728,998$ & $131,510,964$ & $160,239,962$ \\
\hline UT & 0.0013 & 0.0015 & 0.0028 & 0.0024 & 0.0080 & $2,233,169$ & 0.0078 & $5,606,888$ & $14,084,440$ & $19,691,328$ \\
\hline VT & 0.0015 & 0.0030 & 0.0036 & 0.0018 & 0.0060 & 608,827 & 0.0021 & $4,182,732$ & $3,839,829$ & $8,022,561$ \\
\hline VA & 0.0050 & 0.0041 & 0.0067 & 0.0082 & 0.0276 & $7,078,515$ & 0.0248 & $19,317,813$ & $44,643,697$ & $63,961,510$ \\
\hline WA & 0.0048 & 0.0045 & 0.0074 & 0.0079 & 0.0267 & $5,894,121$ & 0.0207 & $18,687,243$ & $37,173,807$ & $55,861,050$ \\
\hline WV & 0.0017 & 0.0016 & 0.0031 & 0.0031 & 0.0104 & $1,808,344$ & 0.0063 & $7,287,607$ & $11,405,099$ & $18,692,706$ \\
\hline WI & 0.0029 & 0.0035 & 0.0046 & 0.0038 & 0.0128 & $5,363,675$ & 0.0188 & $8,957,540$ & $33,828,322$ & $42,785,862$ \\
\hline WY & 0.0014 & 0.0020 & 0.0040 & 0.0028 & 0.0094 & 493,782 & 0.0017 & $6,581,268$ & $3,114,248$ & $9,695,516$ \\
\hline PR & 0.0027 & 0.0035 & 0.0053 & 0.0041 & 0.0137 & $3,808,610$ & 0.0134 & $9,570,651$ & $24,020,636$ & $33,591,287$ \\
\hline Total & & & & & 1.0000 & $285,230,516$ & 1.0000 & $699,583,434$ & $1,798,928,831$ & $2,498,512,266$ \\
\hline
\end{tabular}

Table 6

Root mean squared error (RMSE) of the alternative allocation percentages

\begin{tabular}{lcc}
\hline Allocation score (\%) & Population score (\%) & RMSE \\
\hline 0 & 100 & $22,320,720$ \\
10 & 90 & $20,401,648$ \\
20 & 80 & $19,223,712$ \\
$\mathbf{2 8}$ & $\mathbf{7 2}$ & $\mathbf{1 8 , 9 1 1 , 2 2 0}$ \\
30 & 70 & $18,925,807$ \\
40 & 60 & $19,548,207$ \\
50 & 50 & $21,009,280$ \\
60 & 40 & $23,150,777$ \\
70 & 30 & $25,803,843$ \\
80 & 20 & $28,827,579$ \\
90 & 10 & $32,117,464$ \\
100 & 0 & $35,599,788$
\end{tabular}

Note: Bold type indicates optimal allocation.

scores (according to the year 2000 census data). The root mean squared errors given in Table 6 were used to determine the optimal $28-72 \%$ split after reviewing all possible allocations ranging from $0 \%$ to $100 \%$.

(C) 2007 The Authors.

Journal compilation (C) International Federation of Operational Research Societies 2007 


\section{Evaluation of the subjective judgments and ratings}

As a part of the evaluation of Slice, the eight DMs who participated in the pilot study provided their assessment by completing a survey containing a set of dependent variables. Our choice of dependent variables was influenced primarily by Bharati and Chaudhury's (2004) decision satisfaction model, Benbasat and Lim's (1993) meta-analysis, DeLone and McLean's (1992) usability model, Gallupe et al.'s (1988) effectiveness model, and Limayem and DeSanctis's (2000) decisional guidance model. Collectively, these studies point to the importance of the quality of the decision process and decision quality as key antecedents of users' satisfaction with the use of decision support systems.

Three scales were created: decision process (eight items), decision quality (six items), and overall value-added (four items). Where feasible, items were adapted from items used in previous studies (e.g., Aldag and Power, 1986; Bharati and Chaudhury, 2004; Davis, 1989; DeLone and McLean, 1992; Gallupe et al., 1988; Niederman and DeSanctis, 1995; Srinivasan, 1985; Watson et al., 1988). All items are presented in the Appendix. Each item was evaluated using a 7-point rating scale where $1=$ strongly disagree, $4=$ neutral, and $7=$ strongly agree.

The means (and standard deviations) on the three scales are decision process $=5.81(0.50)$, decision quality $=5.85(0.59)$, and overall value-added $=6.22(0.53)$. All the reliability coefficients (Cronbach's $\alpha$ ) exceeded 0.70 and can be considered good (Nunnally, 1978; p. 245). For the eight decision process items, $\alpha=0.89$; for the six decision quality items, $\alpha=0.86$; and for the four overall value-added items, $\alpha=0.85$. The high $\alpha$ coefficients reflect the high inter-item correlations both within and between scales. This reflects the presence of halo in the data. That is, the DMs tend to form a general impression about Slice, and this general impression influences their ratings of all the items on all the scales.

The Pearson correlations among the three scales are all high and significant $(p<0.05)$. For decision process and decision quality, $r=0.80$. For decision process and overall value-added, $r=0.94$. For decision quality and overall value-added, $r=0.82$. This means that both decision process and decision quality are strong predictors of overall value-added with decision process being a slightly stronger predictor. The multiple regression results show decision process to be the stronger predictor when both decision process and decision quality are entered into the equation simultaneously. However, these results are not especially meaningful because of the high multicollinearity. Further evidence of this phenomenon is found by observing the average inter-item correlation among items on the same scale (average $r=0.54$, a "convergent" correlation) versus the average inter-item correlation among items from different scales (average $r=0.52$, a "discriminant" correlation). In sum, the ratings across the three scales appear to be positive and reflect an overall favorable impression among the DMs about the usefulness of Slice. It is also noteworthy that none of the eight DMs had a mean rating on any of the three scales that was 4 (neutral) or below. That is, all reactions were slightly to very favorable. For example, on value-added, the eight raters' average scores ranged from 5.25 to 7.00 and seven of the raters' scores were 6.00 or higher).

\section{Conclusion and managerial implications}

The pilot study illustrated that DMs viewed Slice very favorably on decision process, decision quality, and overall value-added. It appears that Slice was evaluated favorably because DMs 
viewed it helpful in enhancing the quality of the decision-making process. These perceptions can enhance DMs' confidence in the decision and their belief that those affected by the decisions will view the process and outcomes as fair.

In summary, the structured framework presented in this study has some obvious attractive features. First, the generic nature of Slice allows for the subjective and objective evaluation of a finite number of states and territories on a finite number of threats or responses by a group of DMs. Second, the information requirements of Slice are stratified hierarchically allowing DMs to focus on a small area of the large problem. Third, the built-in inconsistency checking mechanism of AHP helps to identify inconsistencies in judgments at very early stages of the computation process. Fourth, Slice does not dispel subjectivity; it calibrates the subjective weights with the objective weights determined through the entropy method; and it calibrates the subjective probabilities though probability elicitation by extracting expert knowledge about the probability of future events. Fifth, Slice takes into consideration the risk-averse attitude of the DMs through utility maximization.

As Russo and Schoemaker (1989) note, considerable research indicates that DMs can maximize their chances of making the best choice(s) if they find a systematic way to evaluate all the evidence favorable or unfavorable to each alternative, such as the subjective linear model described here. Still, in most applied settings, it is not possible to demonstrate the accuracy of subjective linear models. In contrast, where the same decision is made repeatedly, data on the outcomes of past decisions are available, and one expects the future to resemble the past. In this setting, objective linear models such as multiple regression can be used to determine the optimal set of predictors. For many decisions, including the one described here, there are no objective outcomes of past decisions. For example, there is no objective index that can be used to evaluate whether the fund allocation resulting from Slice or from the current approach is optimal. In such situations, rigorous subjective linear models such as Slice are likely to provide the best hope for optimizing the quality of decisions and the acceptability of those decisions to organizational stakeholders and public.

The final allocation scores depend heavily on the subjective judgments and ratings provided by the DMs. Therefore, it is imperative that these judgments and ratings be perceived as reasonably accurate and fair. If the rating process is viewed by the stakeholders and public as biased, inaccurate, or contaminated by self-serving motives, then fund allocation decisions will be viewed as unfair. In developing subjective judgments and ratings, two types of rating errors can occur. Some rating errors are unintentional. For example, two DMs who agree on the threat of attack on skyscrapers might assign different weights to that event because they interpret the rating scale differently. However, some rating errors such as assigning a higher probability of occurrence to one home state or territory are intentional and reflect self-serving or political motives. In this case, DMs may have the ability to make accurate judgments, but they are unwilling to do so. DMs can play political games and distort their judgments to achieve a desired goal (Kozlowski et al., 1998). Kozlowski et al. (1998) have noted that politics and associated judgment distortions are more likely when (a) there is a direct link between the judgments and desired rewards as in fund allocation decisions, (b) there is a lack of surveillance of DM behavior, and (c) there is a widespread perception that others will distort their judgments. Kozlowski et al. (1998) describe several actions that organizations can take to minimize the role of politics in judgments and ratings. These recommendations include (a) having key DMs serve as role models by providing fair evaluations and discouraging political game playing, (b) allowing other DMs to suggest 
potential improvements to the system itself, (c) ensuring that the evaluation criteria are widely viewed as relevant, (d) using multiple DMs, and (e) making DMs accountable for their evaluations by having to explain the reasons for their judgments. When DMs are motivated to provide accurate judgments, training can enhance the accuracy of the judgments. Hauenstein (1998) reviewed the empirical research in this area and described key elements in successful DM accuracy training. A facilitator should also guide rating sessions to ensure that the same process is applied systematically to all states and territories. In general, it has been shown that facilitation enhances the effectiveness of groups using group decision support systems (Khalifa et al., 2002).

Finally, using a structured, step-by-step approach like Slice is not intended to imply a deterministic approach to homeland security funding allocation. Homeland security funding is a complex problem requiring compromise and negotiation between stakeholders from various branches of government. Slice creates an even playing field to pursue consensus. While Slice enables DMs to crystallize their thoughts and organize data by simultaneously considering both inherently subjective criteria and more objective criteria, it should be used very carefully. As with any decision analysis model, the researchers and practicing managers must be aware of the limitations of subjective estimates.

\section{Acknowledgements}

The author would like to thank the anonymous reviewers and the editor for their constructive suggestions and clear directions.

\section{References}

Aguilar, F.J., 1967. Scanning the Business Environment. Macmillan Company, New York.

Albright, K.S., 2004. Environmental scanning: radar for success. Information Management Journal 38, $38-45$.

Aldag, R., Power, D., 1986. An empirical assessment of computer assisted decision analysis. Decision Sciences 17, $572-588$.

Belton, V., Stewart, T.J., 2002. Multiple Criteria Decision Analysis: An Integrated Approach. Kluwer Academic Publishers, Boston.

Benbasat, I., Lim, L., 1993. The effects of group, task, context, and technology variables on the usefulness of group support systems: a meta-analysis of experimental studies. Small Group Research 24, 430-462.

Beyth-Marom, R., 1982. How probable is probable? A numerical translation of verbal probability expressions. Journal of Forecasting 1, 257-269.

Bharati, P., Chaudhury, A., 2004. An empirical investigation of decision-making satisfaction in web-based decision support systems. Decision Support Systems 37, 87-197.

Bodily, S.E., 1985. Modern Decision Making: A Guide to Modeling With Decision Support Systems. McGraw-Hill, New York.

Brun, W.A.T., Teigen, K.H., 1988. Verbal probabilities: ambiguous, context-dependent, or both? Organizational Behavior and Human Decision Processes 41, 390-404.

Brunet, A., 2005. Grant funding to state and local governments and systematic assessment of vulnerability. Center for Risk and Economic Analysis of Terrorism Events. University of Southern California.

Budescu, D.V., Wallsten, T.S., 1985. Consistency in interpretation of probabilistic phrases. Organizational Behavior and Human Decision Processes 36, 391-405.

Clarke, S.E., Chenoweth, E., 2006. The politics of vulnerability: constructing local performance regimes for homeland security. Review of Policy Research 23, 95-114.

Coats, R.M., Karahan, G., Tollison, R.D., 2006. Terrorism and pork-barrel spending. Public Choice 127, 1-13. 
David, F.R., 1986. The strategic planning matrix - quantitative approach. Long Range Planning 19, 102-107.

David, F.R., 1993. Concepts of Strategic Management (4th edn), Merrill, Columbus.

Davis, F., 1989. Perceived usefulness, perceived ease of use, and user acceptance of information technology. MIS Quarterly 13, 319-340.

DeLone, W.H., McLean, E.R., 1992. Information systems success: the quest for the dependent variable. Information Systems Success 3, 60-95.

Diakoulaki, D., Mavrotas, G., Papayannakis, L., 2000. Objective weights of criteria for interfirm comparisons. Journées du groupe européen Aide Multicritére à la Décision $36^{\mathrm{e}}$, Luxembourg.

Doumpos, M., Zopounidis, C., 2002. Multicriteria Decision Aid Classification Methods. Kluwer Academic Publishers, Boston.

Dyer, J.S., 1990a. Remarks on the analytic hierarchy process. Management Science 36, 249-258.

Dyer, J.S., 1990b. A clarification of 'Remarks on the analytic hierarchy process'. Management Science 36, $274-275$.

Expert Choice. Computer Software, 2004. Decision Support Software, McLean.

Gallupe, R., DeSanctis, G., Dickson, G., 1988. Computer-based support for group problem-finding: an experimental investigation. MIS Quarterly 12, 277-296.

Grabisch, M., Roubens, M., 1999. An axiomatic approach to the concept of interaction among players in cooperative games. International Journal of Game Theory 28, 547-565.

Gupta, S.K., Cozzolino, J.M., 1974. Fundamentals of Operations Research for Management. Holden-Day, San Francisco.

Harker, P.T., Vargas, L.G., 1987. The theory of ratio scale estimation: Saaty's analytic hierarchy process. Management Science 33, 1383-1403.

Harker, P.T., Vargas, L.G., 1990. Reply to 'Remarks on the analytic hierarchy process' by J. S. Dyer. Management Science 36, 269-273.

Hauenstein, N.M.A., 1998. Training raters to increase the accuracy of appraisals and the usefulness of feedback. In: Smither, J.W. (ed.) Performance Appraisal: State-of-the-Art in Practice. Jossey-Bass, San Francisco, pp. 404-442.

Hershey, J.C., Kunreuther, H.C., Schoemaker, P.J.H., 1989. Sources of bias in assessment procedures for utility functions. In: Bell, D.E., Raiffa, H., Tversky, A. (eds) Decision Making: Descriptive, Normative, and Prescriptive Interactions. Cambridge University Press, Cambridge, pp. 422-442.

Keeney, R.L., Raiffa, H., 1976. Decisions with Multiple Objectives: Preference and Value Tradeoffs. Wiley, New York.

Kersten, D., 2005. Spreading security. Government Executive 37, 17-18.

Khalifa, M., Davison, R., Kwok, R.C-W., 2002. The effects of process and content facilitation restrictiveness on GSSmediated collaborative learning. Group Decision and Negotiation 11, 345-361.

Kozlowski, S.W.J., Chao, G.T., Morrison, R.F., 1998. Games raters play: politics, strategies, and impression management in performance appraisal. In: Smither, J.W. (ed.) Performance Appraisal: State-of-the-Art in Practice. Jossey-Bass, San Francisco, pp. 163-205.

Lichtenstein, S., Newman, J.R., 1967. Empirical scaling of common verbal phrases associated with numerical probabilities. Psychonomic Science 9, 563-564.

Limayem, M., DeSanctis, G., 2000. Providing decisional guidance for multicriteria decision making in groups. Information Systems Research 11, 386-401.

McGlashan, R., Singleton, T., 1987. Strategic Management. Merrill, Columbus.

Niederman, F., DeSanctis, G., 1995. The impact of a structured argument approach on group problem formulation. Decision Sciences 26, 451-474.

Nunnally, J.C., 1978. Psychometric Theory. McGraw-Hill, New York.

Pardalos, P.M., Hearn, D., 2002. Multicriteria Decision Aid Classification Methods. Kluwer Academic Publishers, Boston.

Pomero, J-C., Brba-Romero, S., 2000. Multicriterion Decision in Management: Principles and Practice. Kluwer Academic Publishers, Boston.

Reese, S., 2005. Risk-based funding in homeland security grant legislation. Congressional Research Service RL33050, 119.

Roberts, P.S., 2005. Shifting priorities: congressional incentives and the homeland security granting process. Review of Policy Research 22, 437-449.

(C) 2007 The Authors.

Journal compilation (C) International Federation of Operational Research Societies 2007 
Roy, B., 1990. Decision-aid and decision making. European Journal of Operational Research 45, 324-331.

Russo, J.E., Schoemaker, P.J.H., 1989. Decision Traps. Fireside, New York.

Saaty, T.L., 1983. Axiomatic foundations of the analytic hierarchy process. Management Science 32, 841-855.

Saaty, T.L., 1989. Decision making, scaling, and number crunching. Decision Sciences 20, 404-409.

Saaty, T.L., 1990a. Multicriteria Decision Making: The Analytic Hierarchy Process. RWS Publications, Pittsburgh.

Saaty, T.L., 1990b. An exposition of the AHP in reply to the paper 'Remarks on the analytic hierarchy process'. Management Science 36, 259-268.

Saaty, T.L., 1994. How to make a decision: the analytic hierarchy process. Interfaces 24, 19-43.

Saaty, T.L., Vargas, L.G., 2001. Models, Methods, Concepts and Applications of the Analytic Hierarchy Process. Kluwer Academic Publishers, Boston.

Schoemaker, P.J.H., 1993. Multiple scenario development: its conceptual and behavioral foundation. Strategic Management Journal 14, 193-213.

Schoemaker, P.J.H., Russo, J.E., 1993. A pyramid of decision approaches. California Management Review 36, 9-31.

Srinivasan, A., 1985. Alternative measures of system effectiveness: associations and implications. MIS Quarterly 9, 243253.

Tavana, M., Kennedy, D., Mohebbi, B., 1997. An applied study using the analytic hierarchy process to translate common verbal phrases to numerical probabilities. Journal of Behavioral Decision Making 10, 133-150.

Triantaphyllou, E., 2000. Multi-Criteria Decision Making Methods: A Comparative Study. Kluwer Academic Publishers, Boston.

Vanderpooten, D., Vincke, P., 1989. Description and analysis of some representative interactive multicriteria procedures. Mathematical and Computer Modeling 12, 1221-1238.

Vickers, B., 1992. Using GDSS to examine the future European automobile industry. Futures 24, 789-812.

Vincke, P., 1992. Multicriteria Decision Aid. Wiley, New York.

Watson, R.T., DeSanctis, G., Poole, M.S., 1988. Using GDSS to facilitate group consensus: some intended and unintended consequences. MIS Quarterly 12, 463-478.

Zahedi, F., 1986. The analytic hierarchy process - a survey of the method and its applications. Interfaces 16, 96-108.

Zeleny, M., 1982. Multiple Criteria Decision Making. McGraw-Hill, New York.

\section{Appendix}

Decision process items

- The quality of the decision-making process in Slice was good.

- The analysis of the states and territories in Slice showed careful consideration.

- The group's decision-making process in Slice was effective.

- The group's decision-making process in Slice was very structured and systematic.

- The group made suggestions and provided input in Slice.

- Everyone in the group contributed during the decision-making process in Slice.

- The group experienced little conflict during the discussions with Slice.

- I was satisfied with the decision-making process using Slice.

\section{Decision quality items}

- The decision we made using Slice was a good one.

- People who would be affected by the decision made using Slice will probably be satisfied with it.

- The quality of the decision we made using Slice was very good. 
- I am confident about the decision we made using Slice.

- I agree with the final decision that the group made using Slice.

- Everyone in the group felt comfortable with the final decision that we made using Slice.

Overall items - value added

- Slice provided valuable assistance as we made our decisions.

- Slice effectively supported our decision-making.

- Slice enhanced the quality of our group's decision.

- Overall, I find Slice to be useful. 